\title{
Effectiveness of SAMETI (N) Training Programmes on Extension Functionaries
}

\author{
Surekha Sankangoudar* and Poornima Toragal \\ Department of Extension and Communication Management, College of Community Science, \\ University of Agricultural Sciences Dharwad 580005, India \\ *Corresponding author
}

\begin{tabular}{l} 
Ke y w o r d s \\
$\begin{array}{l}\text { SAMETI, Training } \\
\text { programmes, } \\
\text { Extension } \\
\text { functionaries }\end{array}$ \\
\hline Article Info \\
$\begin{array}{l}\text { Accepted: } \\
\text { 26 May } 2020 \\
\text { Available Online: } \\
\text { 10 June } 2020\end{array}$ \\
\hline
\end{tabular}

Keywords

SAMETI, Training programmes,

Extension

Article Info

Accepted:

26 May 2020

10 June 2020

\section{A B S T R A C T}

The State Agriculture Management and Extension Training Institute (SAMETI) as a part of Agricultural Technology Management Agency (ATMA) programme. SAMETI (N) conducts HRD activities in thirteen northern districts of Karnataka and is located in University of Agricultural Sciences, Dharwad, Karnataka. The present study has been carried out to know the effectiveness of training programmes of SAMETI (N) on extension functionaries during 2019 in Belgaum, Dharwad and Gadag districts. The effectiveness was measured in terms of perceived gain in knowledge, perceived job performance and perceived usefulness with 190 extension functionaries, who were trained under SAMETI (N) in the last three years (2015-16, 2016-17 and 2017-18), were considered as the sample for the present study. An ex-post-facto research design was adopted for the study. The findings of the study revealed that, perceived knowledge with an index of 74.39 , perceived job performance with an index of 85.02, Perceived usefulness of the training programmes index was 77.72 . We can conclude that training programmes organized by SAMETI $(\mathrm{N})$ were very effective and found to be useful for the respondents.

\section{Introduction}

Agriculture remains as mainstream of the Indian economy as it provides livelihood to more than half of India's total population. Agricultural extension system is playing a vital role in creating awareness and disseminating innovative technologies to the farming community, in order to reach the agricultural needs and requirements of our country. Since independence extension system has evolved many approaches with the changing dynamics of Indian agriculture.

The Government of India has introduced extension reforms with decentralized extension approach i.e. Agricultural Technology Management Agency (ATMA). Extension Education Institute and SAMETI(N) further disseminate the 
extension to all State agriculture and allied departments. SAMETIs were established to push the reforms through capacity building of extension functionaries by organizing needbased training programmes.

ATMA is conceived as a multi-agency platform bottom-up system for addressing short comings of agricultural extension including convergence of agriculture and allied sectoral services. In Karnataka ATMA programme was implemented during 2005 in two phases. As a part of ATMA, SAMETIs were established for capacity building of extension functionaries by organizing need based training programmes. In Karnataka two SAMETIs are existed, viz., SAMETI (N) and SAMETI (S). SAMETI (N) is located at UAS Dharwad and it is conducting HRD activities for 13 districts of North Karnataka. Other 17 Southern districts of Karnataka are covered by SAMETI (S). SAMETI (N) conducts capacity building programmes regularly based on the needs and as suggested by extension functionaries in the planning workshop. Training is a process through which a person enhances and develops his efficiency and effectiveness at work by improving and updating his knowledge and understanding relevant to his work (Thangjam et al., 2017). Training programmes are major events conducted by SAMETI (N), To study the effectiveness of training programmes conducted by SAMETI(N) the present study has been carried out.

Faiz and Narayanaswamy (2011) carried out a study on profile of Agricultural Officers of Karnataka State Department of Agriculture. A total 35 respondents were considered as the sample for the study. The study revealed that a majority $(71.43 \%)$ of the Agricultural officers had a high level of knowledge, 22.86 per cent had a medium level knowledge and only 17.14 had a low-level knowledge.
Manty (2011) as reported previously, the results revealed that the overall knowledge about ICT tools, it was found that, 62.50 per cent of UASD extension personnel had high level of knowledge category followed by medium $(25.00 \%)$ and low $(12.50 \%)$. In contrary to this 47.00 per cent of KSDA extension personnel had low $(47.50 \%)$ level of knowledge about ICT tools followed by high $(30.00 \%)$ and medium (22.50\%) respectively.

Dhiraj and Pandey (2012) conducted a study on impact of model training course on enhancement of knowledge of extension functionaries in application of scientific potato production technologies in Shimla, Himachal Pradesh. A total 32 extension functionaries were considered as the sample size for the study. The study revealed that a majority $(81.25 \%)$ of the extension functionaries perceived that basic knowledge of potato was highly useful followed by Potato disease management $(75.00 \%)$ economics and marketing in potato $(68.75 \%)$.

Patel et al., (2012) investigated the perceived utility of training programme by extension functionaries. A sample size consisted of 40 respondents. The study revealed that most $(91.66 \%)$ of the extension functionaries had knowledge about monitoring and evaluation technique and three forth of the respondents had a knowledge about steps in monitoring and evaluation process and methods of data collection.

Madhu et al., (2013) conducted a study on capacity building of extension functionaries through training intervention for enhancing job performance. The study was conducted by Extension Education Institute, Rajendranagar. With a sample of 156 respondents from five states viz., Andhra Pradesh, Karnataka, Kerala, Orissa and Tamil Nadu. They reported that majority of the respondents in all the states had medium level of knowledge, 
followed by high and low levels. The areas of knowledge are communication skills, production \& use of audio- visual aids, personality development and Human Resource Development.

Pounraj (2013) conducted a study on job performance of 150 Fisheries Extension Functionaries in State Department Fisheries, Tamil Nadu. They observed that, nearly half of the respondents $(49.34 \%)$ were under high level performance, followed by 26.66 per cent with medium level and the remaining 24 per cent of the respondents was low level.

Debnath et al., (2014) studied on job competence and job performance of the extension personnel of the Department of Agriculture in Tripura State of North-East India. The sample size was 80 extension personnel (40 Agriculture Officers (AOs) and 40 Village Level Workers (VLWs). Data was collected through structured interview schedule. The result found that 40.00 per cent of Agricultural officer belonged to high level job performance category and 34.38 per cent belonged to low category only 25.00 per cent belonged to medium level of job performance category. Whereas, 37.50 per cent of Village Level Workers belonged to medium level of job performance category. An equal per cent (31.25\%) of the Village Level Workers belonged to high- and low-level category.

Goyal et al., (2015) assessed the job performance of Veterinary Surgeons (VSs) in Haryana. Primary data was collected from a sample of 120 (VSs). Majority (55.00\%) of the Veterinary Surgeons were grouped under medium level of job performance.

Hotakar (2018) conducted a study on knowledge and opinion about ATMA among staff and beneficiaries in Northern Karnataka. An "ex-post-facto" research design was adopted. Data was collected from randomly selected 90 beneficiaries and 30 ATMA staff. the study revealed that most $(93.33 \%)$ of the respondents had high level knowledge and 6.67 per cent had medium level. None of the respondents had low level of knowledge.

Kudari (2018) studied on perception of agricultural technology management agency (ATMA) by extension personnel in North Karnataka. The total sample size for the study was 280 extension personnel and data was collected through structured questionnaires. The results indicated that 56.07 per cent of extension personnel belonged to medium level of job performance category, while, 31.43 per cent of them belonged to high level of job performance category and 12.50 per cent were in low level of job performance category.

\section{Materials and Methods}

The present study has been carried out during 2019 in three districts namely, Belagavi, Dharwad and Gadag districts. SAMETI (N) conducts regular training programmes for extension functionaries. Previous three years (2015-16, 2016-17 and 2017-18) training programmes participants list of extension functionaries was obtained from the office of SAMETI (N). From the obtained list, 50 participants extension functionaries from Belagavi, 90 from Dharwad and 50 respondents from Gadag were considered as the sample for the study. Thus total 190 samples were considered for the present study. An ex-post-facto research design was adopted for the study. The data was collected through self-structured, pre-tested questionnaire. To measure the effectiveness of SAMETI $(\mathrm{N})$ activities, factors considered were perceived gain in knowledge, perceived job performance and perceived usefulness of training programmes. Based on the training programme organized by SAMETI $(\mathrm{N})$, statements were prepared and based on the 
responses of respondents, we could identify the effectiveness of SAMETI(N) training programmes.

\section{Results and Discussion}

Table 1 shows perceived gain in knowledge of extension functionaries. To measure the perceived gain in knowledge of extension functionaries, 22 statements were prepared based on the training programmes organized by SAMETI $(\mathrm{N})$ in the last three years (2015, 2016 and 2017) and it was measured on how much per cent they can deal with these aspects based on the training programmes undergone, viz., 1-20\%, 21-40\%, 41-60\%, $61-80 \%$ and $>81 \%$. Based on the scores respondents were categorized into low, medium and high. More than half of the respondents that is 57.89 per cent were in high level of knowledge, about one fourth $(26.84 \%)$ of the respondents were in medium level knowledge and 15.26 per cent of the respondents were still in low knowledge category with the knowledge index 74.39.

The reason might be SAMETI $(\mathrm{N})$ is conducting need-based training programmes to strengthen the capacity of extension functionaries. It also provides the latest information to upgrade their knowledge in agriculture and allied sectors. More over most of the extension functionaries were Graduates, Post Graduates and had high level of mass media participation and they were innovators and had a high-level achievement motivation these factors influenced the extension functionaries to gain in knowledge. Learning is continuous process so, they were utilized the opportunities to acquire the knowledge. So we could find the results high to medium level of knowledge. The low level knowledge category can be taken care in the subject where they need more knowledge they can be given additional training programme for them.
These findings are in line with that of Faiz and Narayanswamy (2011), Manty (2011), Patel et al., (2012) and Hotakar (2018). The above findings reported that most of the extension functionaries belonged to high level of knowledge category to medium level knowledge category.

Table 2 shows Perceived job performance of extension functionaries. To measure the Perceived job performance, based on the training programmes conducted by SAMETI(N), 18 statements were prepared and respondents were asked to respond in three category that is satisfied, partially satisfied and dissatisfied. Overall index was found to be 85.02 i.e., the respondents job performance was to the extent of 85.02per cent. The results revealed that about 89.00 per cent of the respondents were satisfied with their job performance and 11.00 per cent of them were partially satisfied and interesting to note that none of them were dissatisfied with their job performance.

The reasons for good performance might be due to their personal interest in carrying out their duties and many times compulsion or achieving the targets given by the superiors. Now a day's farmers have also become more aware of the facilities available from agriculture and allied departments as these things are given wide publicity from government and sometimes elected members also help in implementation of programmes to keep their supporters happy. These also contribute to the higher job performance. Bimonthly meetings are conducted by the higher officer to review the work progress and sometimes officials from Zilla Panchayat and Secretary at level also monitors the activities along with local MLA and MP's. The extension functionaries are closely supervised by many responsible persons and these factors keep them on their toes to perform their duty in a better way. 
This finding is in line with Debnath et al., (2014) . This study showed, job performance of the respondents were high to medium level category.

Table 3 reveals about perceived usefulness of training programme by extension functionaries. SAMETI (N) conducted different type of training programmes. Training programmes conducted in previous three years were listed. Thirteen topic were identified and asked about its usefulness that is very useful, useful and not useful for them.

Table.1 Over all perceived gain in knowledge of extension functionaries

\begin{tabular}{|l|l|c|c|}
\hline \multicolumn{5}{|c|}{ SI No. } & \multicolumn{1}{|c|}{ Category } & Frequency & Per cent \\
\hline $\mathbf{1}$ & Low $(<52)$ & 029 & 15.26 \\
\hline 2. & Medium $(52$ to 81$)$ & 051 & 26.84 \\
\hline 3. & High $(>81)$ & 110 & 57.89 \\
\hline Overall index of perceived gain in knowledge $\mathbf{7 4 . 7 9}$ & \\
\hline
\end{tabular}

Table.2a Over all perceived job performance of extension functionaries

\begin{tabular}{|c|l|c|c|}
\hline SI No. & Category & Frequency & Per cent \\
\hline 1. & Low $(<12)$ & 00 & 00.00 \\
\hline 2. & Medium (12 to 24) & 21 & 11.05 \\
\hline 3. & High $(>24)$ & 169 & 88.94 \\
\hline
\end{tabular}

Table.3 Over all perceived usefulness of trainings by extension functionaries

\begin{tabular}{|c|c|c|c|}
\hline SI No. & Category & Frequency & Per cent \\
\hline $\mathbf{1 .}$ & Low $(<8)$ & 12 & 06.31 \\
\hline $\mathbf{2 .}$ & Medium $(8$ to 14$)$ & 43 & 22.63 \\
\hline 3. & High $(>14)$ & 135 & 71.05 \\
\hline \multicolumn{2}{|c|}{ Overall index of perceived usefulness } & $\mathbf{7 7 . 7 2}$ & \\
\hline
\end{tabular}

$(n=190)$

Among the respondents 71.05 per cent perceived those training programme were very useful to them and 22.63 per cent of them perceived as useful and 6.31 per cent of them perceived training programme were as not useful to them with the index of 77.72. Most of the extension functionaries expressed that training programmes organized by SAMETI (N) were very useful the reason might be SAMETI $(\mathrm{N})$ organizing trainings based on the needs of the extension functionaries which helped to acquiring new knowledge and skill and also update them with latest research and technology. The topics covered in the trainings were helped in changing the behaviour of the farmers to adopt innovative technologies. They also got hands on experience in trainings through 
demonstrations, field visits. So, extension functionaries felt that training programmes were conducted by SAMETI(N) very used to perform their job in efficient and effective way.

This finding are in line with Dhiraj and Pandey (2012), This study showed, respondents felt training programmes were highly useful to them.

Hence concluded from the study results, the overall perceived gain in knowledge index was 74.39 i.e., overall perceived gain in knowledge was to the extent of 74.39 per cent. Over all perceived job performance index was 85.02 i.e. over all perceived job performance was to the extent 85.02 per cent and over all perceived usefulness index was 77.72 i.e., over all perceived usefulness was to the extent of 77.72 per cent. We could say that the activities organised by SAMETI (N) could influence to increase more than three fourth of extension functionaries, which is necessary to carry out their jobs. Selfconfidence, mass media participation, training programmes attended, innovative proneness, education qualification, work experience and achievement motivation were influenced in perceived gain in knowledge, job performance and usefulness of extension functionaries which in turn says that, whatever efforts made by SAMETI $(\mathrm{N})$ in HRD activities were helping to achieve better in their profession. We could conclude that the training conducted by SAMETI $(\mathrm{N})$ have been very effective in building capacities of extension functionaries, still SAMETI $(\mathrm{N})$ has the scope to improve the efficiency level of the extension functionaries. About one fourth of extension functionaries needs intensive efforts to train them. The trainings can be made more effective by taking the opinion of the extension functionaries and by adopting more practical methods/hands on training programmes.

\section{References}

Debanth, A., Saravanan, R. and Datta, J., 2014, Job competence and job performance of extension personnel of the department of agriculture in Tripura state of North-East India. Int. J. Social Sci., 3(2): 91-112

Dhiraj, K. S. and Pandey, N. K., 2012, Impact of model training course on enhancement of knowledge of extension functionaries in application of scientific potato production technologies. Indian Res. J. Ext. Edu., 12 (13): 95-98.

Faiz, A. and Narayanswamy, B. K., 2011, Profile of trainees undergone training and trainers involved in training at Staff Training Unit, University of Agricultural Sciences, Bangalore. Mysore J. Agric. Sci., 45(4): 945-946.

Goyal, J., Singh, K., Tiwari, M., Lal, S. P., Singh, M. and Khanna, S., 2015, Factors affecting job performance of veterinary surgeons in Haryana. Indian J. Dairy Sci., 68(2): 184-189.

Hotakar, P., 2018, Knowledge and opinion about ATMA among staff and beneficiaries in northern Karnataka. M.H.Sc. Thesis Univ. Agric. Sci., Dharwad, Karnataka (India).

Kudari, M., 2018, A study on perception of agricultural technology management agency (ATMA) by extension personnel in North Karnataka. Ph.D. Thesis, Univ. Agric. Sci., Dharwad, Karnataka (India).

Madhu, B. K., Sailaja, K., Reddy, J. M. and Venugopalreddy, C. H., 2013, Capacity building of extension functionaries through training intervention for enhancing job performance. J. Social Sci. Res., 35:304-324.

Manty, H., 2011, Access and use of ICT tools by extension personnel for transfer of technology in North Karnataka. M. Sc. 
(Agri.) Thesis, Univ. Agric. Sci., Dharwad.

Patel, B. J., Patel, D. B., Sukhadiya, G. A. and Onima, V. T., 2012, Utility of training programme on monitoring and evaluation as perceived by trainees. Gujarat J. Extn. Edn., 23: 135-138.

Pounraj, A., 2013, Job performance of fisheries extension functionaries in
Tamil Nadu. Madras Agric. J., 100(13): 217-223.

Thangjam, D., Singh, K., M., Ram, N. and Singh, O, 2017, Effectiveness of training programmes through perception of KVK trainees in Imphal east district of Manipur. Indian Res. J. Ext. Edu., 17(4): 93-98.

\section{How to cite this article:}

Surekha Sankangoudar and Poornima Toragal. 2020. Effectiveness of SAMETI (N) Training Programmes on Extension Functionaries. Int.J.Curr.Microbiol.App.Sci. 9(06): 3387-3393. doi: https://doi.org/10.20546/ijcmas.2020.906.401 